Nat. Hazards Earth Syst. Sci. Discuss., https://doi.org/10.5194/nhess-2018-187

Manuscript under review for journal Nat. Hazards Earth Syst. Sci.

Discussion started: 1 August 2018

(c) Author(s) 2018. CC BY 4.0 License.

3

4

\section{5}

6

7

8

9

\title{
Quantification of uncertainty in rapid estimation of earthquake fatalities
}

\section{based on scenario analysis}

Xiaoxue Zhang ${ }^{1,2}$, Hanping Zhao ${ }^{1,2}$, Fangping Wang ${ }^{1,2}$, Zezheng Yan ${ }^{1,2}$, Sida Cai ${ }^{1,2} \&$ Xiaowen Mei $^{1,2}$

1.Key Laboratory of Environmental Change and Natural Disaster, MOE, Faculty of Geographical Science,

Beijing Normal University, Beijing, China;

2.Academy of Disaster Reduction and Emergency Management, Ministry of Civil Affairs \& Ministry of

Education, Faculty of Geographical Science, Beijing, China;

Correspondence to: Hanping Zhao (zhaohanping@bnu.edu.cn)

Abstract: The rapid estimation of earthquake fatalities using earthquake parameters is the core basis for emergency response. However, there are numerous factors affecting earthquake fatalities, and it is impossible to obtain an accurate estimation result. The key to solve this problem is quantifying the uncertainty. In this paper, we proposed a new method to estimate earthquake fatalities and quantify the uncertainty based on basic earthquake emergency scenarios. The accuracy of the model is verified by earthquake that occurred during recent year. The preliminary analysis and comparison results show that the model is more effective and reasonable and can also provide a theoretical basis for post-earthquake emergency response.

Keywords: earthquake fatalities, rapid estimation, scenario analysis, uncertainty, information diffusion

\section{Introduction}

The most important assessment after a destructive earthquake is the estimation of fatalities (Samardjieva. 2002). However, a field investigation cannot be conducted quickly, often because of road damage and communication interruption. (Kongar et al. 2015; Yuan and Wang. 2009). Nevertheless, one can estimate earthquake fatalities in a few minutes using earthquake parameters (such as magnitude, intensity and initial time) (Frolova, et al. 2011; Wald, et al. 2008). In addition, it is essential to study the uncertainty of the estimation because there are various uncontrollable factors in the process of estimation. In this sense, a preliminary estimation with uncertainty analysis of earthquake fatalities using available earthquake parameters is a key path in starting the emergency response.

At present, the methods for estimating earthquake fatalities mainly include analytical, semi- 
Nat. Hazards Earth Syst. Sci. Discuss., https://doi.org/10.5194/nhess-2018-187

Manuscript under review for journal Nat. Hazards Earth Syst. Sci.

Discussion started: 1 August 2018

(c) Author(s) 2018. CC BY 4.0 License.

analytical and empirical models (Federal Emergency Management Agency (FEMA), 2005). However, the calculation of analytical and semi-analytical models are based on building damage data, which are not suitable for rapid estimation (Li, et al. 2015; Weng, et al. 2009). During recent years, the empirical model has been widely used in rapid estimation, which depends on statistical analysis using historical loss data. The empirical model provides an important opportunity to quickly and approximately assess the earthquake loss. Regarding the study of the empirical model, Japanese researchers did so relatively early. Kawasumi (1951) proposed a measure to estimate the danger and expectation of the maximum intensity of destructive earthquakes in Japan. Similarly, Ohta et al. (1983) developed an empirical relationship for estimating the number of casualties within the number of completely destroyed houses. A more recent attempt was based on an analysis of strong global earthquakes during the twentieth century, which obtained a loglinear relationship for fatalities as a function of magnitude and population density (Samardjieva. 2002). On the basis of Samardjieva's study, Badal et al. (2005) put forward a quantitative earthquake fatality estimation model that considered the mortality rate. Similarly, Nichols and Beavers (2003) studied the earthquake loss catalog of the twentieth century and established a bounding function with the fatality count and magnitude. Chen et al. (2005) analyzed earthquake cases on mainland China and developed an empirical equation based on the standard of population density and the relationship between the seismic fatalities and the magnitude. Jaiswal et al. (2009) established a mortality model based on population distribution according to rebuilt earthquake case scenes and studied regional earthquake cases (Jaiswal et al. 2010). Generally speaking, the current empirical model for fatality estimation is derived from available historical data and relies on parameter regression analysis. Therefore, there are two problems with the empirical model. First, it will ignore extreme events when there is lack of historical data. Second, most models consider fewer factors and do not consider the influence between know factors and possible unknown factors. It is quite essential to establish a new rapid estimation model of earthquake fatalities that can avoid these problems.

The data or processes used in the empirical model contain considerable uncertainty, and the uncertainty in these components is the source of inaccuracy or error in the estimation results (Gardi et al. 2011; Gall et al. 2009; Wirtz et al. 2014). During recent years, the study of uncertainty in the estimation of earthquake fatalities has mainly regarded the qualitative 
description (Romão, 2016), and there is a relative lack of quantitative research. Qualitative description is the most widely used method to describe the uncertainty in disaster estimation (Van Asselt 2000). There are many linguistic uncertainties when describing the uncertainty in terms of vagueness and context, which can result in an inaccurate qualitative description. The numerical quantification of uncertainty is possible for emergency decision making when the information is partial or not quantifiable during the process of estimation. It is imperative to construct a suitable model to quantify the uncertainty in the estimation of earthquake fatalities.

In this paper, we present a new approach to estimate earthquake fatality expectations and quantify the uncertainty in the estimation, which is expressed as a function of the mortality rate and victims. The basic scenarios are constructed using the magnitude, the initial time and the relationship between the epicentral intensity and the epicentral fortification intensity, and these scenarios consider combinations of parameters. This study not only breaks the traditional empirical model form but also quantifies the uncertainty in the estimation results.

\section{Earthquake fatalities in mainland China}

In general, historical earthquake fatality and exposure data provide a useful basis for future earthquake fatality estimation. We collected destructive earthquake data from earthquakes that occurred on mainland China from 1970 to 2017 as samples. The datasets mainly contain the earthquake parameters (e.g., magnitude, epicentral intensity, epicentral fortification intensity and initial time) and the disaster information (e.g., the number of fatalities and the number of victims); the distribution of the samples is shown in Figure 1. The disaster information was derived from EM-DAT (http://www.emdat.be/), and the earthquake parameters were obtained from PAGER (https://www.pager.com/). 


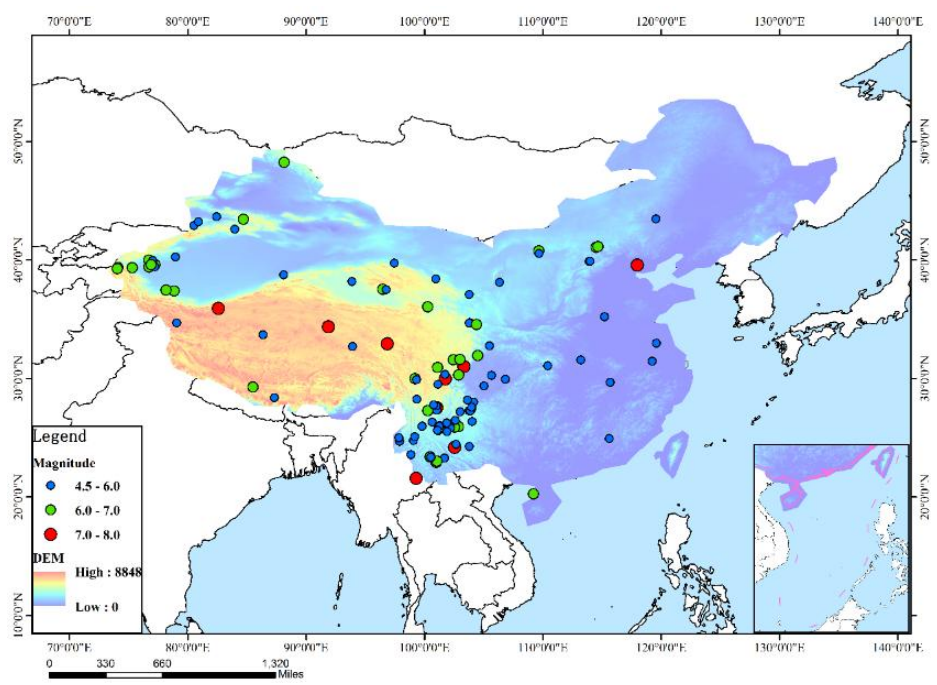

Figure 1. Distribution of historical earthquakes on mainland China from 1970 to 2017

\section{Basic earthquake emergency scenarios}

Scholars have discussed the factors that affect earthquake fatalities, which include magnitude, intensity, initial time, population exposure, housing fragility, and individual factors (Oike, 1991; Nichols, 2003). Moreover, scholars have considered as many factors as they can when modelling. However, some errors remain in each model; thus, the relational expression between the parameters and the number of fatalities is not suitable, or there are still some temporarily non-measurable factors. Therefore, we hoped to identify the main influencing factors via the analysis of historical data. Basic earthquake emergency scenarios were constructed based on a combination of the main factors. A basic scenario combination can better express the relationship between the parameters and earthquake fatalities. Then, information diffusion theory was used to diffuse the sample data based on the basic scenarios considering the temporarily nonmeasurable factors and the extreme event under each scenario.

We collected data on 219 destructive earthquakes that caused casualties in China from 1970 to 2017. Via qualitative analysis using the collected data, the main factors affecting earthquake fatalities were acquired. There is an approximately linear relationship between the magnitude and the number of fatalities (Figure 2). As the magnitude increases, the number of fatalities increases. The relationship between the epicentral intensity and the number of fatalities is shown in Figure 3; the epicentral intensity is mapped to the number of fatalities. The relationship 
Nat. Hazards Earth Syst. Sci. Discuss., https://doi.org/10.5194/nhess-2018-187

Manuscript under review for journal Nat. Hazards Earth Syst. Sci.

Discussion started: 1 August 2018

(c) Author(s) 2018. CC BY 4.0 License.
Natural Hazards and Earth System

Sciences

Discussions
102

103

104

105

106

107

between the number of fatalities and the initial time is relatively vague, as shown in Figure 4.

However, it is evident that the maximum number of fatalities occurred during the period 21:0006:00. The initial time of the earthquake will influence the in-building ratio, the population exposure and the speed of the escape reaction of indoor personnel (Chen 1993; Yang et al. 2007). After analysis, it was found that there was no ideal correspondence between the collapse area and the number of fatalities, as shown in Figure 5.

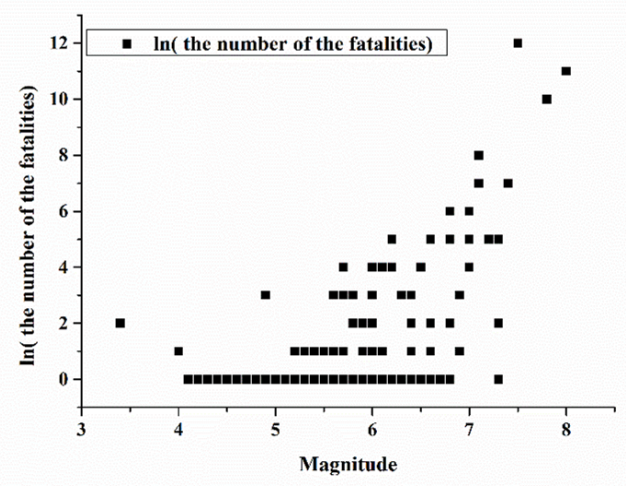

Figure 2. Relationship between the magnitude and the number of fatalities

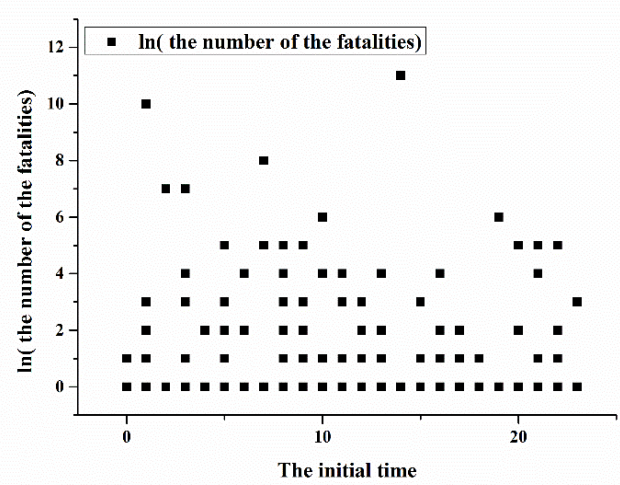

Figure 4. Relationship between the initial time and the number of fatalities

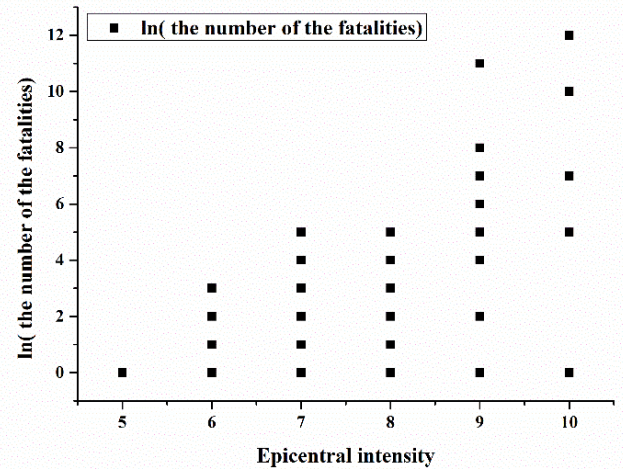

Figure 3. Relationship between the epicentral intensity

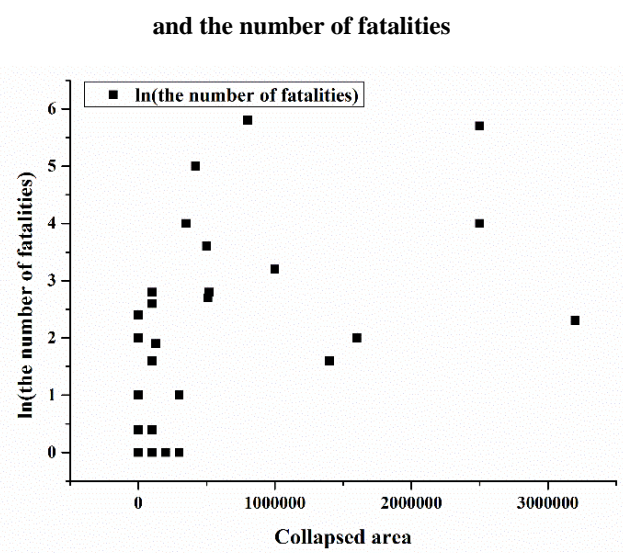

Figure 5. Relationship between the collapsed area and the number of fatalities

Based on the aforementioned analysis, the magnitude, epicentral intensity and initial time were selected as the main parameters used to establish the basic earthquake emergency scenarios. Magnitude can be expected to be the most essential factor in determining earthquake fatalities. The magnitude was divided into three levels $(4.5 \leq \mathrm{M}<6,6 \leq \mathrm{M}<7$ and $7 \leq \mathrm{M} \leq 8$ (M means 
Nat. Hazards Earth Syst. Sci. Discuss., https://doi.org/10.5194/nhess-2018-187

Manuscript under review for journal Nat. Hazards Earth Syst. Sci.

Discussion started: 1 August 2018

(c) Author(s) 2018. CC BY 4.0 License.

magnitude)) according to the principle of magnitude division in the earthquake emergency programming of China (The National Earthquake Emergency Plan, 2012). On the basis of the magnitude division, the relationship between the empricial intensity and the fortification intensity was used to indirectly express the building damage information. The relationship between magnitude $(\mathrm{M})$ and epicentral intensity $\left(\mathrm{I}_{0}\right)$ is as follows : $\mathrm{M}=0.58 I_{0}+1.5(\mathrm{~GB} / \mathrm{T} 17742)$. As the fomula shows, when the magnitude is greater than 6 , the empirical intensity is greater than 7.75. However, there are fewer historical earthquakes with a regional fortification intensity greater than 8 in China. Therefore, the basic earthquake emergency scenarios do not consider the scenario with an epicentral intensity less than the epicentral fortification intensity when the magnitude is greater than 6. In addition, the initial time of the earthquake is an important factor affecting staff reaction. During early morning or night, most of the population is sleeping in residential buildings; thus, they cannot take protective measures. In contrast, during the day, most of the population is at work. Thus, the initial time was devided into two periods: day (06:0020:59) and night (21:00-05:59). Finally, the basic earthquake emergency scenarios were constructed based on a combination of the magnitude, intensity, and initial time of the earthquake

(Figure 6).

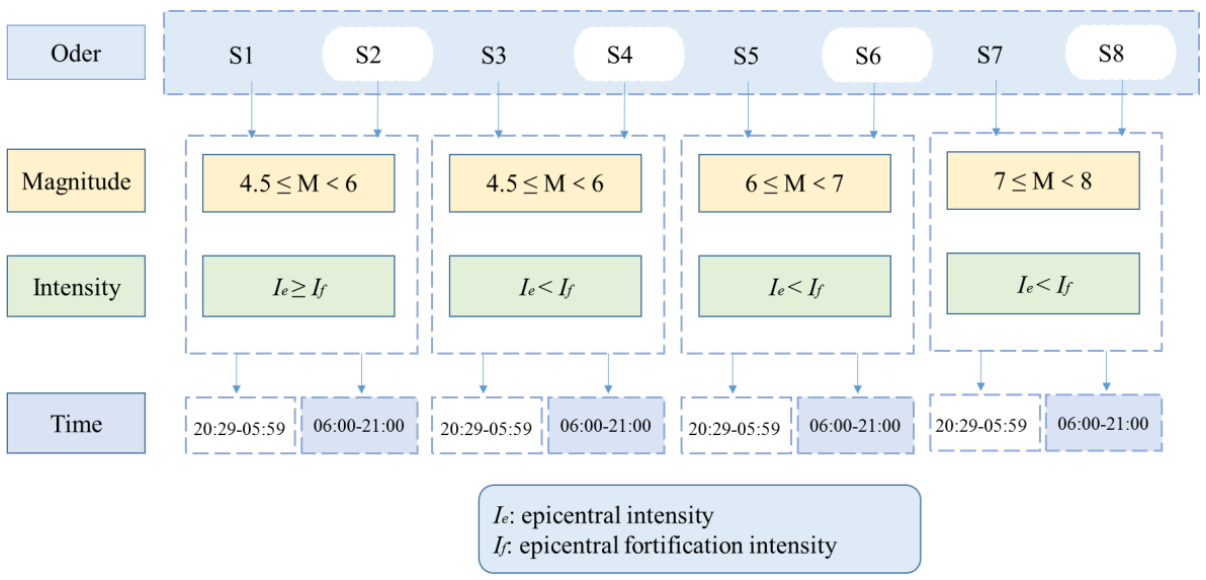

Figure 6. Framework of basic earthquake emergency scenarios

The objective of the rapid estimation model of earthquake fatalities based on scenario analysis is to estimate the fatality expections and the uncertainty in the fatality interval. The sample data were classified into each scenario based on the framework of the basic earthquake emergency scenarios. Then, the classified samples were devided into two sets (Table 1). One set 
consisted of $80 \%$ of sample data, which were selected randomly selected from each scenario for model construction. Another set was composed of the remaining $20 \%$ of the samples, which was used to verify the accuracy of the model.

Table 1. Data sample size and data usage

\begin{tabular}{cc}
\hline Sample size & Data usage \\
\hline 175 (random selection of $80 \%$ of the samples & Model construction \\
under each scenario) & \\
44 (random selection of $20 \%$ of the samples & Verification \\
under each senario) & \\
\hline
\end{tabular}

\section{Methodology}

We needed a functional form describing the fatalities with the victim and moritality rate. After the earthquake, the China Earthquake Administration will rapidly publish information on the earthquake, including the magnitude, the geographic coordinates of the epicentre, and the source mechanism solution (Wang, et al. 2013). The intensity distribution is acquired by the earhquake parameter information and the seismic intensity elliptical attenuation model (Wang, et al. 2000; Wu, et al. 2010). The number of victims is calculated with the area of each intensity and the population density. To derive an earthquake fatality rapid estimation function, one needs to compile the mortality rate statistical analysis under each scenario using observations from past earthquakes. The outline of the approach is as follows:

$$
\mathrm{D}=E\left(S_{t}\right) \times \sum_{I=5}^{I_{\max }} k_{I} A_{I} P_{I}
$$

where $\mathrm{D}$ is the number of fatalities; $E\left(S_{t}\right)$ is the mortality rate expectation of scenario $S_{t}$; $A_{I}$ is the affected area of the intensity $I ; I_{\max }$ is the maximum intensity for an earthquake; $P_{I}$ is the population density of the intensity $I$, and parameter $k_{I}$ is the ratio of the population affected by the earthquake, as determined from the damage degree table provided by the National Disaster Reduction Center (Fan et al., 2008).

To obtain the mortality rate function beyond the framework of the basic earthquake emergency scenarios, we needed to use the observed data of historical earthquakes to compile a mortality rate expectation under each scenario. However, when dividing the samples into each 
scenario, the sample size will be small, and it is difficult to obtain the relation equation using traditional mathematical statistics. Therefore, the indirect approach of this study consisted of information diffusion theory to obtain the mortality rate. First, the actual observed values for the mortality rate under one scenario were set as matrix $\mathrm{X}=\left\{\mathrm{x}_{1}, \mathrm{x}_{2}, \ldots, \mathrm{x}_{m}\right\}$, where $x_{i}$ is the actual observed values of an earthquake, and $m$ is the total number of earthquake events. At the same time, the actual recorded mortality rate and historical extreme event (the earthquake event with an extreme mortality rate) under one scenario were considered to build the domain $U=$ $\left\{u_{1}, u_{2}, u_{3}, \ldots, u_{n}\right\}$. Here, $u_{j}$ is the arbitrary discrete real value in the interval $\left[u_{1}, u_{n}\right]$, and $n$ is the total number of discrete points. Then, the sample value $x_{i}$ was diffused to the domain $\mathrm{U}$ according to normal information diffusion. The normal information diffusion expression is as shown in Equation (2):

$$
f(x)=\frac{1}{h \sqrt{2 \pi}} \exp \left[-\frac{\left(x_{i}-u_{j}\right)^{2}}{2 h^{2}}\right] i=1,2, \ldots, m ; j=1,2, \ldots, n
$$

where $h$ is the information diffusion coefficient, and different values are taken according to the size of the sample $(h=0.8146 \times(b-a), m=5 ; h=0.5690 \times(b-a), m=6 ; h=$ $0.4560 \times(b-a), m=7 ; h=0.3860 \times(b-a), m=8 ; h=0.3362 \times(b-a), m=9 ; h=$ $0.2986 \times(b-a), m=10 ; h=2.68516 \times(b-a), m \geq 11$.) (Huang,2012).

The domain $\mathrm{U}$ obtains the information from the mortality rate sample matrix $\mathrm{X}$ with the normal diffusion. After this, the sample information is normalized via the process of normal information diffusion. We acquired the discretization information of each domain point $u_{j}$. Therefore, the mortality rate expectation $E\left(S_{t}\right)$ can be denoted as follows:

$$
\begin{gathered}
E\left(S_{t}\right)=\frac{\sum_{i=1}^{\mathrm{m}} f_{i}\left(u_{j}\right) \times\left(\sum_{j=1}^{n} f_{i}\left(u_{j}\right)\right)^{-1}}{\sum_{j=1}^{n} \sum_{i=1}^{m} f_{i}\left(u_{j}\right) \times\left(\sum_{j=1}^{n} f_{i}\left(u_{j}\right)\right)^{-1}} \times u_{j} \\
i=1,2, \ldots, m ; j=1,2, \ldots, n ; t=1,2, \ldots 8
\end{gathered}
$$

where $u_{j}$ is the point of the domain, $S_{t}$ is the order of the basic earthquake emergency scenario, and the number of scenarios is 8 .

The discretized domain under each scenario is averagely divided into six levels according to the classification of the type of disaster (emergency situation, crisis situation, minor disaster, moderate disaster, major disaster, catastrophe (Eshghi and Larson, 2008)). Hence, the uncertainty of the mortality rate can be expressed as the possibility of each level of the mortality rate. The 
Nat. Hazards Earth Syst. Sci. Discuss., https://doi.org/10.5194/nhess-2018-187

Manuscript under review for journal Nat. Hazards Earth Syst. Sci.

Discussion started: 1 August 2018

(c) Author(s) 2018. CC BY 4.0 License.

probability of each level can be denoted as follows:

$$
\mathrm{P}\left(u_{\alpha}<u \leq u_{\beta}\right)=\sum_{j=\alpha}^{\beta} \frac{\sum_{i=1}^{\mathrm{m}} f_{i}\left(u_{j}\right) \times\left(\sum_{j=\alpha}^{\beta} f_{i}\left(u_{j}\right)\right)^{-1}}{\sum_{j=\alpha}^{\beta} \sum_{i=1}^{m} f_{i}\left(u_{j}\right) \times\left(\sum_{j=\alpha}^{\beta} f_{i}\left(u_{j}\right)\right)^{-1}} 1<\alpha<\beta<n
$$

where $\mathrm{P}$ is the probability of the level (the interval with $u$ is less than $u_{\alpha}$ and is equal or greater than $\left.u_{\beta}\right), \alpha$ is the minimum value of the discrete level point, and $\beta$ is the maximum value of the discrete level point.

\section{Mortality rate in each scenario}

The collected historical destructive earthquake sample belongs to scenario $\mathrm{S}_{1}$ (Table 2), which constitutes the mortality rate matrix $X=\left\{2.459 \times 10^{-4}, 2.758 \times 10^{-4}, 0.757 \times 10^{-4}, 0,0.001 \times 10^{-}\right.$ $\left.{ }^{4}, 1.886 \times 10^{-4}, 0.141 \times 10^{-4}, 0.023 \times 10^{-4}, 0,0\right\}$. According to the maximum value and minimum value of the mortality rate in the matrix and the precision requirements, we selected $0.000 \times 10^{-4}$ as the minimum value, $2.950 \times 10^{-4}$ as the maximun value, and $0.050 \times 10^{-4}$ as the interval value. Therefore, the domain $\mathrm{U}=\left\{0,0.050 \times 10^{-4}, 0.100 \times 10^{-4}, 0.150 \times 10^{-4}, \ldots, 2.950 \times 10^{-4}\right\}$.

Table 2. Historical earthquakes on mainland China under scenario S1

\begin{tabular}{|c|c|c|c|c|c|c|}
\hline \multicolumn{2}{|c|}{ Time } & \multirow{2}{*}{ Epicentral location } & \multirow{2}{*}{ Magnitude } & \multirow{2}{*}{$\begin{array}{c}\text { Number } \\
\text { of fatalities }\end{array}$} & \multirow{2}{*}{$\begin{array}{l}\text { Number } \\
\text { of victims }\end{array}$} & \multirow{2}{*}{ Mortality rate } \\
\hline Year-month-day & Hour-min-second & & & & & \\
\hline 1983-11-07 & 05:09:45 & Shandong Heze & 5.9 & 46 & 187000 & $2.459 \times 10-4$ \\
\hline $1989-10-18$ & 03:10:40 & Shanxi Datong & 5.8 & 29 & 105140 & $2.758 \times 10-4$ \\
\hline $1989-11-20$ & $03: 18: 42$ & Chongqing Jiangbei & 5.2 & 4 & 52800 & $0.757 \times 10-4$ \\
\hline $1992-11-30$ & 01:38:00 & Sichuan Shiqu & 5.4 & 0 & 27000 & 0 \\
\hline $1996-09-25$ & 03:24:00 & Yunnan Lijiang & 5.7 & 1 & 7690000 & $0.001 \times 10-4$ \\
\hline 2001-05-24 & $21: 10: 43$ & Yunnan Ninglang & 5.8 & 2 & 10605 & $1.886 \times 10-4$ \\
\hline $2008-08-20$ & 05:35:00 & Yunnan Yingjiang & 5.0 & 5 & 355395 & $0.141 \times 10-4$ \\
\hline 2010-01-31 & 05:36:00 & Sichuan Suining & 5 & 1 & 437000 & $0.023 \times 10-4$ \\
\hline 2011-11-01 & $00: 21: 28$ & Xinjiang Yining & 5.6 & 0 & 143000 & 0 \\
\hline 2012-12-07 & 22:08:00 & Xinjinag Ruoqiang & 5.1 & 0 & 29751 & 0 \\
\hline
\end{tabular}

According to the normal information diffusion (Equation (1)), the information carried by the mortality rate sample matrix $\mathrm{X}$ is spread to the domain $\mathrm{U}$. Thereafter, the sample information 
Nat. Hazards Earth Syst. Sci. Discuss., https://doi.org/10.5194/nhess-2018-187

Manuscript under review for journal Nat. Hazards Earth Syst. Sci.

Discussion started: 1 August 2018

(c) Author(s) 2018. CC BY 4.0 License.
Natural Hazards and Earth System

Sciences

Discussions

(c) $\underset{\mathrm{BY}}{(\mathrm{i})}$

is normalized, and we can accquire the discretization information of each sample. Based on Equation (2), calculating the probability of each domain by weighting the information points and the mortality rate expectation, the mortality rate expectation under scenario $\mathrm{S} 1$ is 0.839 . The mortality rate expectation of all the scenarios can be acquired using the same process. The sample size and the mortality rate expectation of each scenario are shown in Table 3.

Table 3. Sample size and mortality rate expectation in each scenario

\begin{tabular}{ccccccccc}
\hline Scenario S & S1 & S2 & S3 & S4 & S5 & S6 & S7 & S8 \\
\hline Sample size & 10 & 32 & 33 & 50 & 19 & 27 & 5 & 7 \\
Moritaty rate & & & & & & & & \\
expectation & $8.4 \times 10^{-5}$ & $6.06 \times 10^{-5}$ & $1.44 \times 10^{-5}$ & $0.914 \times 10^{-5}$ & $43.2 \times 10^{-5}$ & $7.95 \times 10^{-5}$ & $300 \times 10^{-5}$ & $100 \times 10^{-5}$ \\
\hline
\end{tabular}

\section{Quantification of uncertainty in mortality rate estimation}

The rapid estimation of earthquake fatalities is vital for emergency response during the early hours following the event. We can know both the actual record for the historical earthquakes as well as the empirical model-estimated fatalities for the historical events. There is a small difference among the different empirical models as long as the empirical model can answer critical questions, such as whether a particular earthquake requires a response, and if so, at what level (level 1, level 2, level 3, level 4). With the addition of a rapid estimation model based on scenario analysis, we have also proposed a fatality-based alert scale that provides an estimation of the likelihood of a range of fatalities caused by an earthquake. The overall dispersion is associated with the model's prediction for the past earthquakes in that country or region, and then one uses such a measure for determining the uncertainty associated with the model's future estimates. The estimation for the probability of each mortality rate range is shown in Figure 7. 
Nat. Hazards Earth Syst. Sci. Discuss., https://doi.org/10.5194/nhess-2018-187

Manuscript under review for journal Nat. Hazards Earth Syst. Sci.

Discussion started: 1 August 2018

(c) Author(s) 2018. CC BY 4.0 License.

\section{(c) (1)}

\section{Natural Hazards and Earth System Sciences \\ Discussions}
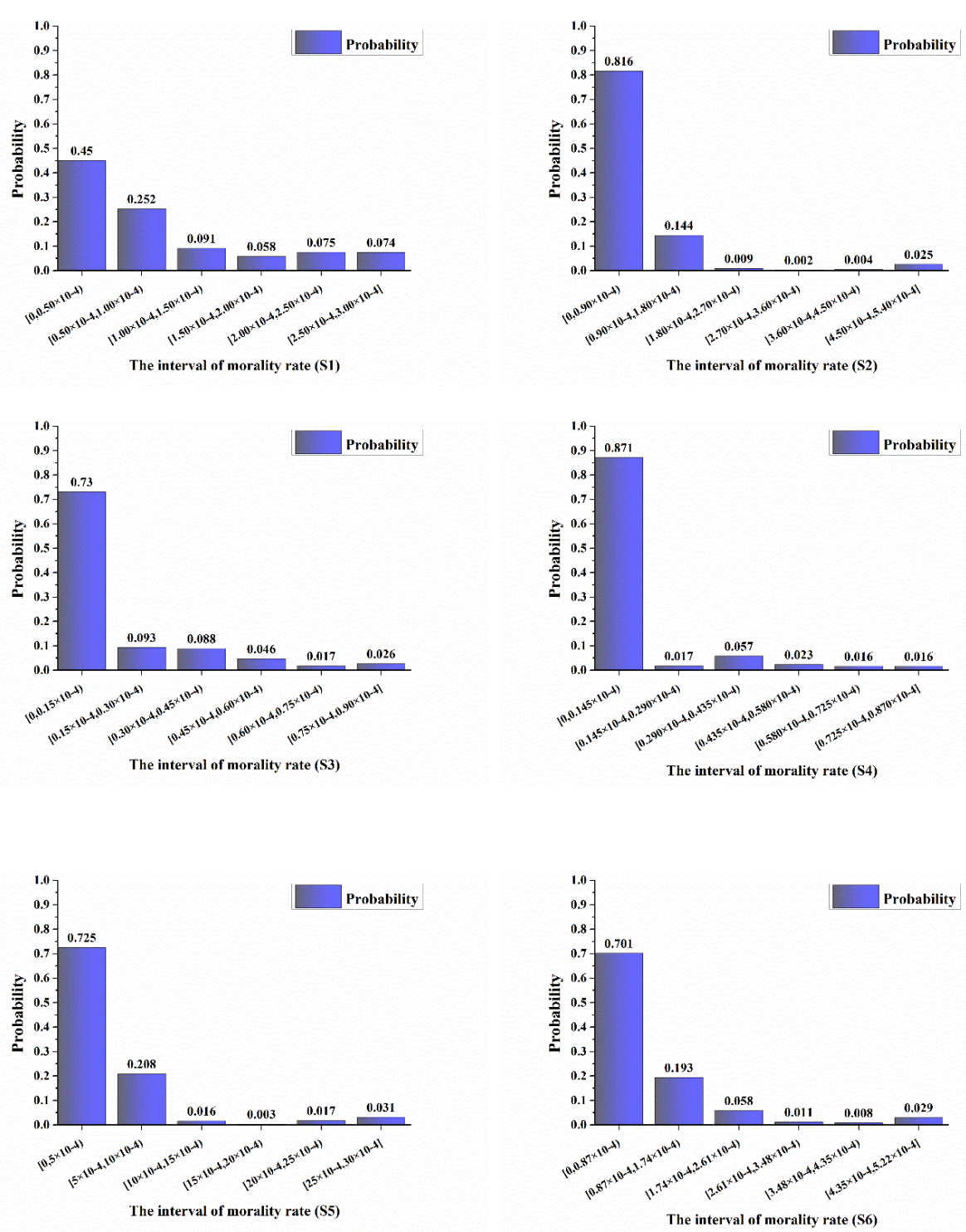
Nat. Hazards Earth Syst. Sci. Discuss., https://doi.org/10.5194/nhess-2018-187

Manuscript under review for journal Nat. Hazards Earth Syst. Sci.

Discussion started: 1 August 2018

(c) Author(s) 2018. CC BY 4.0 License.
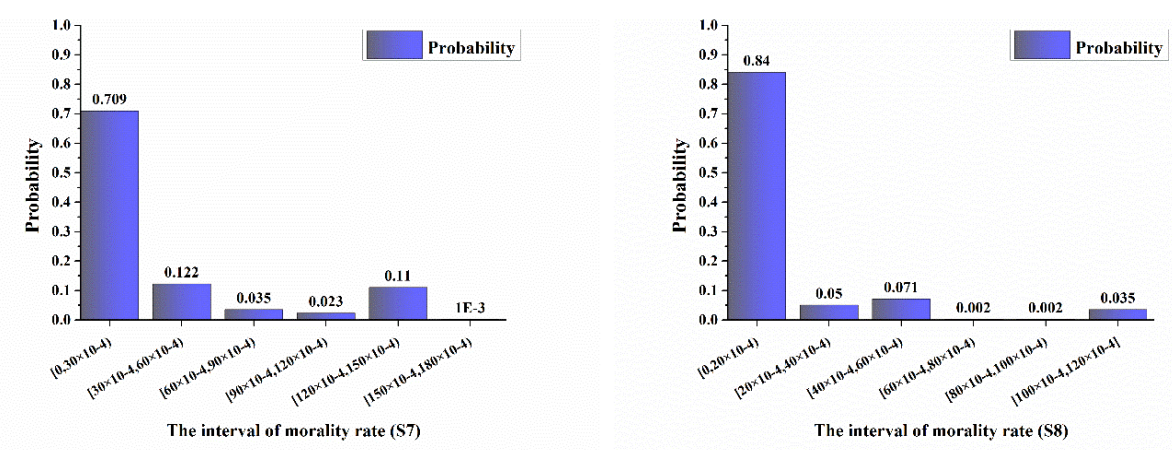

Figure 7. Probability of the mortality rate under each scenario

\section{Verification}

The empirical model has been verified using historical earthquakes. Out of a total of 219 earthquakes for which data was collected in this study, 44 (20\% of the samples under each scenario were randomly selected) were estimated using the rapid estimation model, and the results are shown in Table 4. Incidentally, we assessed the accuracy of the model via a comparison between the recorded fatalities and estimated fatalities. Among the outliers, the model predicted fewer fatalities for an earthquake (M 6, 9 July 1979) in China, i.e., Jiangsu Liyang, that killed 41 people. At the same time, there were some overestimated fatalities, such as for the earthquake in Hebei Zhangbei (M 6.2, 10 January 1998) and the earthquake in Sichuan Wenchuan (M 8, 12 May 2008). Among the remaining events, the preliminary estimates were within an order of magnitude of the recorded deaths. The number of fatalities calculated using the model was the same order of magnitude as the actual recorded number for more than $95 \%$ of the events. The same order of magnitude will not influence the level of the emergency decision, which is very important for rapid post-earthquake rescue.

Table 4. Verification of historical cases

\begin{tabular}{cccccc}
\hline Scenario & Time & Epicentral location & Magnitude & Actual record & Model calculation \\
\hline \multirow{2}{*}{ S1 } & $2001-05-23$ & Yunnan Ninglang & 5.5 & 2 & 1 \\
& $2004-05-04$ & Qinghai Delingha & 5.5 & 0 & 0 \\
\hline \multirow{2}{*}{ S2 } & $2012-12-07$ & Xinjiang Ruoqiang & 5.1 & 0 & 3 \\
& $1993-08-07$ & Sichuan Muchuan & 5 & 4 & 5
\end{tabular}


Nat. Hazards Earth Syst. Sci. Discuss., https://doi.org/10.5194/nhess-2018-187

Manuscript under review for journal Nat. Hazards Earth Syst. Sci.

Discussion started: 1 August 2018

(c) Author(s) 2018. CC BY 4.0 License.

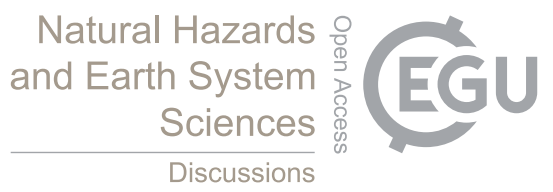

(c) (1)

\begin{tabular}{|c|c|c|c|c|c|}
\hline & $2003-10-25$ & Gansu Shandan & 5.8 & 9 & 11 \\
\hline & $2007-07-20$ & Xinjiang Tekesi & 5.7 & 0 & 5 \\
\hline & 2011-03-10 & Yunnan Yingjiang & 5.8 & 25 & 12 \\
\hline & 2013-04-17 & Yunnan Eryuan & 5 & 0 & 7 \\
\hline & 2013-08-31 & Yunnan Xianggelila & 5.9 & 3 & 5 \\
\hline \multirow{7}{*}{ S3 } & 2006-08-25 & Yunnan Zhaotong & 5 & 1 & 1 \\
\hline & $2008-12-26$ & Yuanan Ruili & 4.9 & 0 & 4 \\
\hline & 2008-04-21 & Gansu Sunan & 4.2 & 0 & 0 \\
\hline & $2003-11-13$ & Gansu Dingxi & 5.1 & 1 & 0 \\
\hline & $2001-02-23$ & Sichuan Yajiang & 5.6 & 3 & 10 \\
\hline & 2005-08-02 & Yunnan Huize & 5.3 & 0 & 10 \\
\hline & 1995-03-19 & Xinjiang Heshuo & 5.1 & 0 & 3 \\
\hline \multirow{13}{*}{ S4 } & $1995-04-26$ & Sichuan Muchuan & 5.1 & 0 & 0 \\
\hline & 1996-01-09 & Xinjiang Shawan & 5.6 & 0 & 0 \\
\hline & 2001-04-12 & Yunnan Shidian & 5.6 & 2 & 1 \\
\hline & 1996-01-16 & Sichuan Rongchang & 4.3 & 0 & 0 \\
\hline & 2013-03-29 & Xinjiang Jichang & 5.6 & 0 & 0 \\
\hline & 1999-11-01 & Shanxi Datong & 5.3 & 0 & 20 \\
\hline & 2011-08-11 & Xinjiang Jiashi & 5.6 & 0 & 0 \\
\hline & 2012-01-08 & Xinjiang Heshuo & 5 & 0 & 0 \\
\hline & $1997-01-25$ & Yunnan Mengla & 5.1 & 0 & 0 \\
\hline & 1997-05-31 & Fujian Liancheng & 5.2 & 0 & 2 \\
\hline & $1995-02-18$ & Yunnan Cangyuan & 5.1 & 0 & 0 \\
\hline & 2013-12-01 & Xinjiang Keping & 5.3 & 0 & 0 \\
\hline & 2003-05-04 & Xinjiang Jiashi & 5.8 & 1 & 1 \\
\hline \multirow{4}{*}{ S5 } & 1998-01-10 & Hebei Zhangbei & 6.2 & 49 & 116 \\
\hline & $1989-09-22$ & Sichuan Xiaojin & 6.6 & 1 & 23 \\
\hline & 2005-04-08 & Xizang Zhongba & 6.5 & 0 & 2 \\
\hline & 2015-07-03 & Xinjiang Pishan & 6.4 & 3 & 17 \\
\hline
\end{tabular}


Nat. Hazards Earth Syst. Sci. Discuss., https://doi.org/10.5194/nhess-2018-187

Manuscript under review for journal Nat. Hazards Earth Syst. Sci.

Discussion started: 1 August 2018

(c) Author(s) 2018. CC BY 4.0 License.
Natural Hazards and Earth System

Sciences

Discussions

(c) (i)

\begin{tabular}{cccccc} 
& $2008-10-05$ & Xinjiang Wuqia & 6.8 & 0 & 6 \\
\hline & $1979-07-09$ & Jiangsu Liyang & 6 & 41 & 15 \\
S6 & 1989-04-15 & Sichuan Liangshan & 6.4 & 8 & 3 \\
& $1991-02-25$ & Xinjiang Keping & 6 & 0 & 3 \\
& $2003-08-16$ & Neimenggu Chifeng & 6.1 & 4 & 2 \\
& $2012-08-12$ & Xinjiang Yutian & 6.2 & 0 & 75 \\
\hline S7 & $1995-10-24$ & Yunnan Wuding & 6.5 & 58 & 262540 \\
\hline S8 & 1976-07-27 & Hebei Tangshan & 7.5 & 242769 & 122200 \\
& $2008-05-12$ & Sichuan Wenchuan & 8 & 69227 & 254
\end{tabular}

The main purpose of the verification for the uncertainty was to optimize the estimation result. Furthermore, the possible fatality interval was necessary to provide the basis for emergency decisions when needing to consider indeterminate factors during the process, particularly when the main factors for assessment were difficult to acquire. To verify the accuracy of the quantified results, we used the random selection of $20 \%$ of the samples under each scenario. The results show (Table 5) that under the same scenario, the frequency of events with a small mortality rate was higher, and the frequency of catastrophic events was lower. There is an advantage of the model in that the mortality rate distribution can cover all possible historical scenarios. To a certain extent, this compensates for the lack of extreme events during the fitting of the historical data. The results were obtained in the form of interval probability statistics, which provide the basis for the subsequent emergency optimization.

Table 5. Verification of the probability of the mortality rate interval

\begin{tabular}{ccccccc}
\hline Scenario & Interval I & Interval II & Interval III & Interval IV & Interval & Interval VI \\
& & & & & V & \\
\hline S1 & $100 \%$ & $0 \%$ & $0 \%$ & $0 \%$ & $0 \%$ & $0 \%$ \\
S2 & $100 \%$ & $0 \%$ & $0 \%$ & $0 \%$ & $0 \%$ & $0 \%$ \\
S3 & $84 \%$ & $5 \%$ & $11 \%$ & $0 \%$ & $0 \%$ & $0 \%$ \\
S4 & $94 \%$ & $0 \%$ & $3 \%$ & $0 \%$ & $3 \%$ & $0 \%$ \\
S5 & $100 \%$ & $0 \%$ & $0 \%$ & $0 \%$ & $0 \%$ & $0 \%$
\end{tabular}


Nat. Hazards Earth Syst. Sci. Discuss., https://doi.org/10.5194/nhess-2018-187

Manuscript under review for journal Nat. Hazards Earth Syst. Sci.

Discussion started: 1 August 2018

(c) Author(s) 2018. CC BY 4.0 License.

\begin{tabular}{rrrrrrl} 
S6 & $71 \%$ & $29 \%$ & $0 \%$ & $0 \%$ & $0 \%$ & $0 \%$ \\
S7 & $100 \%$ & $0 \%$ & $0 \%$ & $0 \%$ & $0 \%$ & $0 \%$ \\
S8 & $80 \%$ & $0 \%$ & $0 \%$ & $0 \%$ & $20 \%$ & $0 \%$ \\
\hline
\end{tabular}

\section{Estimation for recent earthquakes}

With socio-economic changes, the previous analysis based on historical data may be inconsistent with recent data. Therefore, it is necessary to conduct further verification for the applicability and accuracy of the model using destructive earthquakes that have occurred during recent years. The results of the model calculation were compared to the recorded results. The result and error of the victim estimation is shown in Figure 8. The number of victims calculated via the model is of the same order of magnitude as the recorded number, and the error of the estimation results is less than $30 \%$, which is in line with the requirements of the National Disaster Reduction Committee and the Ministry of Civil Affairs Disaster Reduction Center for the rapid estimation of a disaster.

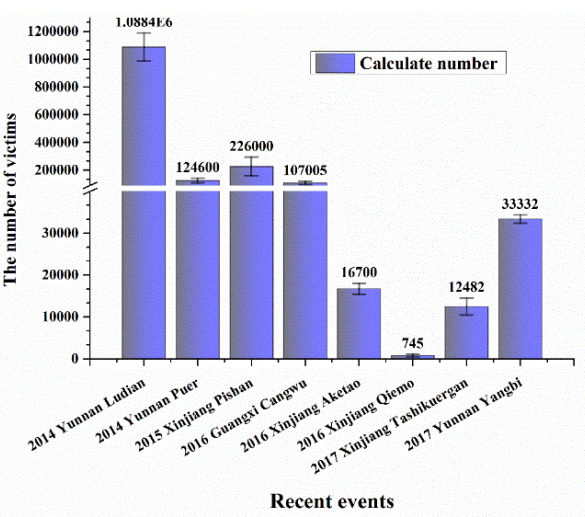

Figure 8. Estimation of the earthquake victims in recent years

The number of fatalities during each earthquake was estimated based on the estimation result for the victims. In addition, two models were chosen for comparison, and the selection of the model here considered that the impacts of the empirical models have regionally varied. Thus, we selected two empirical models with Chinese samples, but with different sample numbers and different forms; the comparision results are shown in Table 6 . The first method was proposed by Liu et al (2012), which set the epicentral intensity as the main parameter, and the magnitude and average population density were auxiliary parameters in the model. There is a large deviation in 
Nat. Hazards Earth Syst. Sci. Discuss., https://doi.org/10.5194/nhess-2018-187

Manuscript under review for journal Nat. Hazards Earth Syst. Sci.

Discussion started: 1 August 2018

(c) Author(s) 2018. CC BY 4.0 License.

the estimation result of Yunnan Puer (2014). The reason for this may be that the auxiliary parameter is the average population density in the affected area rather than the unit statistics, which did not consider the population distribution. The second method was proposed by Xiao (1991). The overall evaluation result of this eatimation model was good. However, there was a poor result for Yunnan Ludian (2014). The reason for this was that the sample age chosen by the model was rather old.The accuracy rate is defined as the total number of events divided by the number of events for which the estimation results are the same grade as the actual records. The rapid estimation model based on scenario analysis has a higher accuracy and is more suitable for rapid estimation via the comparision.

Table 6. Estimation results of each method

\begin{tabular}{ccccccc}
\hline & \multicolumn{2}{c}{ Victims } & \multicolumn{2}{c}{ Fatalities } \\
\cline { 2 - 7 } Earthquake events & Actual & Model & Actual & Model & First method & Second method \\
& record & calculation & record & calculation & calculation & calculation \\
\hline Xinjiang Taerkushigan (2017) & 12482 & 14485 & 8 & 1 & 5 & 0 \\
Yunnan Yangbi (2017) & 33332 & 27000 & 0 & 2 & 2 & 0 \\
Guangxi Cangwu (2016) & 107005 & 101778 & 0 & 6 & 14 & 0 \\
Xinjiang Qiemo (2016) & 745 & 1100 & 0 & 0 & 5 & 64 \\
Xinjiang Aketao (2016) & 16700 & 18000 & 0 & 1 & 31 & 0 \\
Xinjian Pishan (2015) & 226000 & 156094 & 3 & 12 & 47 & 1 \\
Yunnan Ludian (2014) & 1088400 & 986439 & 617 & 427 & 1017 & 18 \\
Yunnan Puer (2014) & 124600 & 123000 & 1 & 53 & 471 & 4 \\
Accuracy rate & - & $100 \%$ & - & $87.5 \%$ & $50 \%$ & $75 \%$ \\
\hline
\end{tabular}

The estimation results of the Yunnan Ludian earthquake (2014) and the Xinjiang Tashikuergan earthquake (2017) were not the same order of magnitude of the actual records. These two scenarios should be considered as the extreme events because of their mortality rates. The fatality interval of Yunnan Ludian (2014) was estimated by the model as [582,680], and the probability was 0.071 . For the Xinjiang Tashikuergan earthquake, the fatality interval was $[8,10]$, and the probability was 0.026 . The interval estimation of the fatalities in the model can consider the extreme events with larger mortality rates but small probability. 
Nat. Hazards Earth Syst. Sci. Discuss., https://doi.org/10.5194/nhess-2018-187

Manuscript under review for journal Nat. Hazards Earth Syst. Sci.

Discussion started: 1 August 2018

(c) Author(s) 2018. CC BY 4.0 License.

Table 7. Validation of the model interval

\begin{tabular}{|c|c|c|c|c|c|}
\hline \multicolumn{2}{|c|}{ Earthquake events } & \multicolumn{4}{|c|}{ Fatalities } \\
\hline \multirow[b]{2}{*}{ Year } & \multirow[b]{2}{*}{ Location } & \multirow[b]{2}{*}{ Actual record } & \multicolumn{3}{|c|}{ The interval } \\
\hline & & & Model calculation & & Probability \\
\hline & & & & & \\
\hline 2014 & Yunnan Ludian & 617 & 427 & {$[0,88)$} & 0.817 \\
\hline 2014 & Yunnan Puer & 1 & 53 & {$[0,61)$} & 0.725 \\
\hline 2015 & Xinjian Pishan & 3 & 12 & {$[0,14)$} & 0.817 \\
\hline 2016 & Guangxi Cangwu & 0 & 6 & {$[0,2)$} & 0.871 \\
\hline 2016 & Xinjiang Aketao & 0 & 1 & {$[0,9)$} & 0.725 \\
\hline 2016 & Xinjiang Qiemo & 0 & 0 & {$[0,1)$} & 0.871 \\
\hline 2017 & Xinjiang Taerkushigan & 8 & 1 & {$[0,1)$} & 0.730 \\
\hline 2017 & Yunnan Yangbi & 0 & 2 & {$[0,1)$} & 0.871 \\
\hline
\end{tabular}

\section{Conclusion and discussion}

Based on the study of earthquake data from mainland China (1970-2017), we proposed a new approach for rapidly estimating earthquake fatalities and quantifying the uncertainty. The main factors of the basic earthquake emergency scenarios were magnitude, intensity (the relationship between the epicentral intensity and the epicentral fortification intensity) and initial time, which were used to express the possible earthquake scenarios. For verification of the model, we not only verified using the recorded number but also presented a comparison to the actual recorded fatalities of historical earthquakes. The fatality estimation results were mostly of the same magnitude as the actual record, and the accuracy of the results were higher than that of the compared empirical model. In addition, the mortality rate interval in the model can effectively cover the high probability of mortality as well as extreme events. Based on the current study, the following aspects were mainly improved:

1. During the actual emergency process, the information on on-site earthquakes will be acquired as time progresses. Therefore, how to update the results with the updated information is in need of further study.

2. With the development of remote sensing and unmanned aerial vehicle (UAV) technology, images can be used after the earthquake for damage estimation. The real-time evaluation results 
Nat. Hazards Earth Syst. Sci. Discuss., https://doi.org/10.5194/nhess-2018-187

Manuscript under review for journal Nat. Hazards Earth Syst. Sci.

Discussion started: 1 August 2018

(c) Author(s) 2018. CC BY 4.0 License.

Natural Hazards and Earth System

Sciences

Discussions

(c) $\underset{\mathrm{BY}}{(i)}$

297

298

299

300

301

302

303

304

305

306

307

308

309

310

311

312

of regional earthquake damage can be acquired. We can obtain relatively accurate information for local regions. Thus, how to extrapolate the local information to estimate the global demand may need further study.

Xiaoxue Zhang analyzed and historical data and also guided focus model design and implementation. Hanping Zhao, Fangping Wang, Zezheng Yan, Sida Cai, Han Wang $\&$ Xiaowen Mei guided focus model design and implementation.

Competing interests. The authors declare they have no conflicts of interest

Acknowledgements. This project was supported by the National Natural Science Foundation of China (NSFC: 41471424) and the National Key Research and Development Program of China (2017YFB0504102).

\section{References}

Asselt Van. Perspectives on uncertainty and risk: the PRIMA approach to decision support. Perspectives on Uncertainty \& Risk, 407-417, 2000.

Badal J, Vázquez, Prada M, Álvaro González. Preliminary Quantitative Estimation of Earthquake Casualties and Damages. Natural Hazards, 34, 353-374, 2005.

Chen Jiayu. Probability of the original time of earthquake affecting the casualty. Journal of catastrophology, 2, 13-16, 1993.

Chen Q F, Hongliang M I, Huang J. A Simplified Approach to Earthquake Risk in Mainland China. Pure \& Applied Geophysics, 162, 1255-1269, 2005.

Larson R C, Eshghi K. Disasters: lessons from the past 105 years. Disaster Prevention \& Management, 17, 6282, 2008

Federal Emergency Management Agency (FEMA), Improvement of nonlinear static seismic analysis procedures, FEMA 440, Washington, DC, United States: Applied Technology Council, 2005.

Fan Yida, Yang Siquan, Wang Lei, et al. Study on urgent monitoring and assessment in Wenchuan earthquake. Journal of remote sensing, 12, 858-864, 2008. 
Nat. Hazards Earth Syst. Sci. Discuss., https://doi.org/10.5194/nhess-2018-187

Manuscript under review for journal Nat. Hazards Earth Syst. Sci.

Discussion started: 1 August 2018

(c) Author(s) 2018. CC BY 4.0 License.

Frolova N, Larionov V, Bonnin J. Earthquake Casualties Estimation in Emergency Mode. Human Casualties in Earthquakes. Springer Netherlands, 107-123, 2011.

Gall M, Borden K A, Cutter S L. When do losses count? Six fallacies of natural hazards loss data. Bulletin of the American Meteorological Society, 90, 799-809, 2009.

Gardi A, Valencia N, Guillande R, et al. Inventory of uncertainties associated with the process of tsunami damage assessment on buildings (SCHEMA FP6 EC co-funded project). Natural Hazards \& Earth System Sciences, 11, 883-893, 2011.

GB/T17742, The Chinese seismic intensity scale, 2008.

Huang Chongfu. Risk analysis and management of natural disasters. Science press, 215,223,2012.

Jaiswal K, Wald D J, Hearne M. Estimating Casualties for Large Earthquakes Worldwide Using an Empirical Approach. U.s.geological Survey, 2009.

Jaiswal K, Wald D. An Empirical Model for Global Earthquake Fatality Estimation. Earthquake Spectra,26, 1017-1037, 2010.

Kongar I, Esposito S, Giovinazzi S. Post, earthquake estimation and management for infrastructure systems: learning from the Canterbury (New Zealand) and L'Aquila (Italy) earthquake. Bulletin of Earthquake Engineering,1, 32, 2015.

Kawasumi, H. Measures of Earthquake Danger and Expectancy of Maximum Intensity throughout Japan as Inferred from the Seismic Activity in Historical Times. Earthquake, Res. Inst, 29, 469-482,1951.

Liu Jinlong, Lin Junqi. Study on estimation method for earthquake casualty based on epicentral intensity. Journal of natural disasters, 5, 113-119, 2012.

Nichols J M, Beavers J E. Development and Calibration of an Earthquake Fatality Function. Earthquake Spectra, 19, 605-633, 2003.

Ohta Y, Goto N, Ohashi H. An Empirical Construction of Equations for Estimating Number of Victims at an Earthquake, 36, 463-466,1983.

Oike K. A discussion on the relation between the magnitude and the number of the dead by earthquakes. Proc. of the Int. Seminar on Earthquake. Prediction and Hazard Mitigation Technology. Tsukuba, 333-341, 1991. Romão X, Paupério E. A framework to assess quality and uncertainty in disaster loss data. Natural Hazards, $83,1-26,2016$.

Samardjieva E. Estimation of the Expected Number of Casualties Caused by Strong Earthquakes. Bulletin of the Seismological Society of America, 92, 2310-2322, 2002. 
Nat. Hazards Earth Syst. Sci. Discuss., https://doi.org/10.5194/nhess-2018-187

Manuscript under review for journal Nat. Hazards Earth Syst. Sci.

Discussion started: 1 August 2018

(c) Author(s) 2018. CC BY 4.0 License.

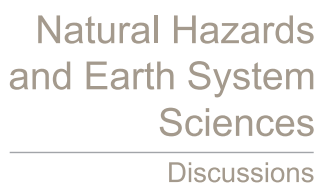

(c) (1)

355 The national earthquake emergency plan [EB/OL ] .(2012, 08, 28). http://www.gov.cn/yjgl/2012,09/21/

356

357

358

359

360

361

362

363

364

365

366

367

368

369

370

371

372 content_2230337. htm.

Wald D J, Earle P S, Allen T I, et al. Development of the US Geological Survey's PAGER system (Prompt Assessment of Global Earthquakes for Response). Journal of Automatic Chemistry, 1, 40-2, 2008.

Wirtz A, Kron W, Löw P, et al. The need for data: natural disasters and the challenges of database management. Natural Hazards, 70,135-157, 2014.

Wang Decai, Ni Sidao, Li Jun. research status of rapid assessment on seismic intensity. Progress in geophys, 28, 1772-1784,2013. (in Chinese)

Wang Suyun, Yu Yangxiang, Gao Ajia, et al. Development of attenuation relations for ground motion in china. Earthquake research in China,16, 99-106, 2000. (in Chinese)

Wu Lixin, Li Zhifen, Wang Zhi, et al. Rapid assessment of earthquake disaster: with Yushu earthquake as an example. Science and technology review,28, 38-43, 2010. (in Chinese)

Xiao Guangxian. Rapid estimation of disaster losses in post, earthquake. Journal of catastrophology, 4,16-21, 1991. (in Chinese)

Yuan Y, Wang D. Path selection model and algorithm for emergency logistics management. Computers \& Industrial Engineering, 56, 1081-1094, 2009. (in Chinese)

Yang Jieying, Li Yongqiang, Liu Lifang, et al. Effect of three earthquake elements on seismic casualty. Journal of seismological research, 30,182-187, 2007. (in Chinese) 